\title{
Technological Innovation in Industry and the Role of The Royal Society
}

\author{
Christopher M. Snowden FRS, FREng \\ Vice-Chancellor, University of Surrey, Guildford, Surrey. GU3 1DF UK \\ Vice-chancellor@surrey.ac.uk
}

\begin{abstract}
Summary
This paper examines the interplay between industrial and academic research and explores how innovation stimulated by the Royal Society has influenced technological development in business and industry over the past fifty years. The trend for universities to foster the creation of spin-out companies has grown significantly over the last twenty years, whilst universities and government simultaneously appreciated the potential value of intellectual property and increasingly formalised interaction between industry and academia. Prior to this the flow of ideas, discoveries and technology from universities to industry relied largely on individuals. Examples of how academics, industrialists and Fellows of the Royal Society have influenced and contributed to industrial research and the world's technology base will be explored. The presentation will examine the supportive role played by the Royal Society through research grants, innovation awards, and distinguished Research Fellowships such as the Industry Fellowships Scheme. The most recent initiative to support scientific and technological ventures shows a new direction for the Royal Society in contributing to innovation through its Enterprise Fund.
\end{abstract}

Key Words: technology innovation, enterprise and the Royal Society.

\section{Introduction}

One of the establishing features of the Royal Society was that it would be a force to benefit the British economy. In this respect the role the Royal Society has to play in technological innovation in industry remains an important part of its portfolio.

Technology innovation and its industrial application first became strongly evident during the industrial revolution of the $18^{\text {th }}$ and $19^{\text {th }}$ centuries when individuals such as Robert Stephenson, James Watt, Humphry Davy and Michael Faraday, all Fellows of the Royal Society, came to the fore and were celebrated for their contributions to both technology and the economy. The pace of scientific innovation and its acceptance by the public and business community increased during the $20^{\text {th }}$ century. The appreciation that science makes important contributions to society became especially evident with major breakthroughs in medicine and health, such as Fleming's discovery of penicillin to treat bacterial infections which drove the early growth of the pharmaceutical industry in the middle of the last century. Progressively the process of discovery and the monetary or strategic value that may be created has been recognised by businesses and governments. This has led to a move away from associating invention and discovery purely with individuals and many important inventions and discoveries are now made 
within a corporate environment in large research and development organisations, funded by major technology companies.

\section{The Role of Universities in Innovation and Industry}

Academia continues to have a very important role to play in both fundamental science and in the initial development of technological discoveries. The importance of this to both the institutions' and the nation's economy has been appreciated in recent years by both government and the universities themselves. Mowery and Rosenberg wrote in their text of 1989 that they believed in the benefits of greater industrial involvement in university research, which at the time was counter to the concerns present in both the USA and UK ${ }^{1}$. They commented on the effectiveness in the USA of universities contributing to industrial research, especially through the education of large numbers of engineers and scientists and contrasted this with British industrial research, which at the time they viewed as limited by low university enrolment. They also discussed the effectiveness of public policy toward technology.

Collaboration in research and development between universities and industry started to increase after World War II when industry needed the resources and expertise of academic researchers to strengthen their product development capabilities. Arrow, in his much cited paper of 1959, discussed the funding of 'invention' by public bodies, including universities, and the interplay with the private sector from the perspective of the economic value and impact of invention ${ }^{2}$. Over the past twenty five years the recognition and engagement of universities with the innovation, knowledge transfer and technology transfer process has increased dramatically. Up to 1980 the exploitation of innovation in universities had in general been very much left to individual scientists and engineers and their own entrepreneurial interests, with the possible exception of the recognition of the value of drug discovery, which some universities already benefited from financially. Examples of companies that were formed by entrepreneurial academics, but without the support of their universities, include Oxford Instruments in 1959 and Filtronic in 1977. Oxford Instruments was founded by Martin and Audrey Wood with an academic base in Oxford's Physics Department. Filtronic was founded by David Rhodes, exploiting his microwave filter research interests that he had established in the Department of Electronic and Electrical Engineering at Leeds.

After this time, interest in commercial exploitation of research by UK universities led to the formation of spin-out companies and the recognition of benefits from licensing of intellectual property. Richards ${ }^{3}$ describes the growth of the spin-out culture at Oxford during the last twenty years and process and funding routes that facilitate the growth of successful companies from research and intellectual property created in universities.

1 D.C. Mowery, N. Rosenberg, Technology and the Pursuit of Economic Growth, (Cambridge University Press, New York, 1989)

22 K.J. Arrow, Economic Welfare and the Allocation of Resources for Invention, P-1856-RC, pp1-23 (The RAND Corporation, Santa Monica California, December 1959).

3 G. Richards, Spin- Outs: Creating Business from University Intellectual Property, First Edition (Harriman House, Petersfield, 2009) 
The rise of interest in universities engaging technology enterprise activities probably has its roots in the United States in the middle of the last century. Stanford, MIT and Harvard strongly influenced the emergence of high technology companies in California and Massachusetts, often benefiting from funding available from the US government's defence department (DoD). Later a similar combination of intellectual capability and DoD funding, often through the Small Business Innovation Research programme established in 1982, led to the rapid growth of other research clusters, such as in the Research Triangle of North Carolina. The Bay-Dole Act in 1980, allowed universities to patent federally funded research and exploit this intellectual property. This lead to a ten fold increase in patent generation with an associated rapid growth in licensing and spin-out activity.

The UK has generally had a more risk-averse approach to funding innovation and although the National Research Development Corporation was established in 1948 to commercialise inventions created using publicly funded research, the UK did not see any significant growth in academic-enterprise until the early 1980s. This coincided with a change in taxation policy in the UK, which encouraged venture capital funding, often necessary to fund new technology companies. In 1987, universities were formally recognised as owning intellectual property developed using government funding and were encouraged to engage more strongly in knowledge transfer. Since that time, knowledge transfer and enterprise activities, often based around technology, have grown dramatically and in 2008 the Higher Education Funding Council of England reported that UK higher education institutions generated $f 1.3$ Bn knowledge transfer, growing at a rate of $20 \%$ whilst generating 220 spin-out companies in that year ${ }^{4}$. In $2007 / 8$ university spin-outs employed close to 14,000 staff with a turnover of $£ 1.1 \mathrm{Bn}^{4}$. The Royal Society's report 'The Scientific Century: securing our future prosperity', recognises that over the last fifteen years, UK universities have responded vigorously to the challenge of increasing knowledge transfer into industry ${ }^{5}$. It also recognises that the support and incentives our universities receive play key roles in encouraging translation, commercialisation and knowledge exchange.

Throughout the period 1950-1990 universities in North America and UK formed research parks which provide a close connection between academic innovation in universities and businesses - especially those with strong entrepreneurial leadership such as startups and spin-outs. Examples of especially successful research parks and technology clusters in the USA and UK include Stanford Research Park, University Park at MIT, Research Triangle Park (North Carolina), Surrey Research Park; Cambridge, Manchester, Oxford, Southampton and Warwick Science Parks; Peel Park (East Kilbride) and Adastral Park Ipswich. Royal Society Fellows have had a major part to play in these parks including the one at Surrey which was established by Anthony Kelly FRS in the early 1980s. Professor Lord Rees, President of the Royal Society presided over the official opening of new facilities at Chesterford Research Park in 2009. Research parks are now widely used globally to help concentrate and support technology companies.

4 Higher Education - Business and Community Interaction, Reference 2008/2, HEFCE, 2008.

Surveyhttp://www.hefce.ac.uk/pubs/hefce/2008/08_22/ also

http://www.hefce.ac.uk/news/hefce/2008/hebci.htm

5 The Scientific Century: securing our future prosperity, The Royal Society (March 2010) 
The last ten years have seen increased investment in research and support for innovation in the UK public sector and this has stimulated considerable activity between universities, industry and business. In the nine years to 2008 , the number of patents granted to universities rose by $136 \%$ and consultancy income rose $222 \%$. The establishment of the Technology Strategy Board (TSB), initially as an advisory board to government departments in 2004 and subsequently as an independent body ('arm's length' from government) in July 2007, has had a significant impact on accelerating innovation and creating value in technology companies. The TSB supports the Knowledge Transfer Partnerships, which have proven extremely effective in linking university research and support to small to medium size enterprises (SMEs); Knowledge Transfer Networks for a number of science, engineering and technology based sectors. Innovation Platforms have been implemented, which are programmes intended to stimulate innovative solutions within UK businesses.

Often many innovations and the route to exploitation require multi-disciplinary expertise. Universities present an ideal environment in which to nucleate multi- and inter-disciplinary research and innovation. The rise in multi-disciplinary research led the Royal Society to introduce its successful 'Interface', the first new journal for over 150 years, as a collaborative venture developed in conjunction with the Engineering and Physical Sciences Research Council. This has been instrumental in supporting cross-disciplinary relationships between engineering and physical sciences and life sciences in the UK. In less than three years, 'Interface' became the fourth most highly-cited interdisciplinary journal in the world, behind 'Science', 'Nature' and the Proceedings of the National Academy of Sciences. It was developed in response to pressure from scientists who were finding few places to publish inter-disciplinary work that bridges the physical and life sciences, such as the mathematical modelling of infectious diseases, or the engineering of new organisms. 'Interface' is ideal for supporting the dissemination of discoveries in the area of synthetic biology where the investigators are drawn from disciplines as diverse as engineering, biology and computer science. The Royal Society is now planning a cross-disciplinary journal which will be called 'Interface Focus' with publication on-line and in printed form.

\section{Supporting Researchers and Innovators}

Support for individuals engaged in innovation has relied historically on research council funding or the support of wealthy benefactors. In the early stages of innovation, typically beyond the basic research stage, it used to be difficult to secure funding to allow individuals to develop their ideas to the point where it could be the basis of a product, company or license arrangement. This stage of innovation work used to fall outside the remit of research councils and prior to the formation of organisations such as the Technology Strategy Board and seed funding within universities, many individuals would fail to win the support they needed to take their ideas through to a commercial phase when venture capital, private equity or other sources of funds then become accessible.

The Royal Society's Brian Mercer Awards for Innovation were established in 2001 to provide meaningful funding for individuals or groups to develop an already proven concept or prototype through to the creation of a near-market product for commercial exploitation. This is intended to help facilitate the inventors to take the project to the point where the 
prospect of venture capital becomes a reality. Dr Mercer was an enthusiastic inventor and entrepreneur and these awards aim to encourage these qualities in the next generation of scientists. Early stage ideas and concepts can be funded from the Brian Mercer Feasibility Awards scheme, which provides initial support to test the feasibility of a project. This enables holders to investigate the technical and economical feasibility of commercialising an aspect of their scientific research, possibly in conjunction with a third party and to such a point where an industrial or commercial collaboration can be established. These awards are focused in areas of built environment, clean technology, energy, nanoscience and nanotechnology.

\section{Case Study}

Support from the Royal Society played a fundamental roll in technological innovation and successful exploitation of a new osmosis process that led to the rapid and successful floatation of a company on AIM in 2008. Professor Adel Sharif, Director of the Centre for Osmosis Research and Applications (CORA) at the University of Surrey, was awarded The Royal Society's Brian Mercer Senior Award for Innovations in Science and Technology in 2005. The Centre's research activities in the area of osmosis science have resulted in a number of inventions in the areas of desalination, water treatment, and renewable energy. These discoveries have the capacity to significantly change the economic and performance characteristics of industries such as desalination, water treatment, power generation, oil, chemical and energy industries that use or produce large quantities of dilute solutions. Desalination has the potential to create secure water supplies for many countries around the world. The $f 250 \mathrm{k}$ Brian Mercer Award helped fund the development of a new manipulated osmosis technology for seawater desalination.

The University of Surrey established Surrey Aquatechnology Ltd in 2005, using its own seed fund, with Professor Sharif as the founding director, to commercialise the IP and research outputs of CORA, especially the work that had been supported by the Mercer Award earlier that year. Surrey Aquatechnology was subsequently merged with Modern Water and the new entity was floated on the London AIM market in June 2007 creating an initial market value of $f 70 \mathrm{~m}$. http://www.royalsoc.ac.uk/news.asp?id=6757 Sharif's core technology of a manipulated osmosis desalination process converts seawater to drinking water, using a selectively permeable membrane. It achieves this with a significant reduction in capital and operating costs as it reduces energy use by the desalination plant and lowers the consumption and disposal of hazardous chemicals. Modern Water has subsequently built a desalination plant in Gibraltar, the first in the world to use manipulated osmosis, that produced its first fresh water in September 2008 and they supplied a further manipulated osmosis plant to Oman in 2009. The company maintains a research collaboration with the university that has produced a further six desalination-related patents. Professor Sharif and Modern Water were the winners of the Energy/Environmental award of the pan-European Enterprise ACES Award at the Royal Academy of Engineering in Stockholm on $2^{\text {nd }}$ December 2008 for their innovative development of water purification desalination technologies.

Recent winners of Brian Mercer Awards include nanotechnology innovators Dr Andrea Ferrari from the University of Cambridge (2007) to develop polymer based ultrafast pulse lasers for applications such as data transmission, micromachining and medical diagnostics; 
Dr Andrew Nelson from the University of Leeds (2008) for developing a device to detect toxicity of nanoparticles (such as those in toothpaste and sun screen lotions) in the water system; built-environment innovators Professor David Stuckey from Imperial College (2007) who is developing a revolutionary waste water recycling technology; and Professor Kirill Horoshenkov (2008) with a novel acoustic technique for assessing sewer pipes.

\section{Industry Fellowships}

The Royal Society supports over 600 research appointments through its various schemes. The Society's Industry Fellowships Scheme, which is funded by the Royal Society and the UK's Engineering and Physical Sciences Research Council, the Biotechnology and Biological Sciences Research Council, the Natural Environment Research Council, Rolls Royce plc and Astra Zeneca aims to enhance knowledge transfer in science and technology between industry and academia by supporting researchers for up to two years. This scheme allows academic scientists to work on collaborative projects with industry or alternatively for a scientist or engineer in industry to work on a collaborative project with a research group in a university or not-for-profit organisation. It is hoped that this will foster long term relationships and corporate links. The scheme encourages work with spin-out companies and small-medium enterprises. The Society's Leverhulme Trust Senior Research Fellowships support shorter research periods, but includes both universities and industrial research organisations.

Although not aimed at industrial collaboration, the Royal Society's Dorothy Hodgkin Fellowships are available to provide support to scientists and engineers at an early stage of their career, and are designed to help them to progress to a permanent position. They are aimed specifically at researchers who require a flexible working pattern due to personal circumstances including parental, caring responsibilities and health issues. In some cases they can provide a bridge between academic research and real-world application. This may take the form of a traditional link with a technology company (possibly through sponsorship) or more recently some Dorothy Hodgkin Fellows have participated in the Member of Parliament-Scientist pairing scheme which facilitates a different route to dissemination and public understanding, linking areas such as science and health with politics.

\section{Royal Society Fellows and their Role in Industry, Enterprise and Technology Transfer}

Many technology companies have benefited from the contributions of Fellows and in many cases they were founding members of these companies. Amongst the many Fellows of the Royal Society who have founded or played major roles in the growth of technology companies are David Payne, co-inventor of the erbium doped fibre amplifier, founder York Technologies (now PK Technology inc) and SPI lasers; David Rhodes, who founded Filtronic based on his award winning filter technologies; Sir Richard Friend world renowned for his research on carbon-based semiconductors and founder of Cambridge Display technology and Plastic Logic; Steve Furber, designer of microcomputers and principal designer at Acorn and ARM; Peter Lawrenson, founder of 
Switched Reluctance Drives (SRD); Sir Martin Sweeting, founder of Surrey Satellite Technology which led to the largest ever cash-spin out of a company from a university.

Other visionary scientists have contributed to innovations that have fundamentally changed the way that scientifically-driven industries operate. Such an example is Sir John Sulston, who saw the building and establishment of the Wellcome Trust Sanger Institute between 1993 and 1994 and subsequently participated in the mapping, sequencing and analysis of genomes and contributed a major part to the Human Genome Project. What had seemed impossible in the early 1990s had been achieved by Sulston and colleagues within ten years and is playing a key role in transforming diagnosis, prevention and treatment of many common diseases ${ }^{6,7}$.

Another example of the role that Fellows have played in revolutionising a technology industry and its application is found in the work of César Milstein (with the then postdoctoral assistant Georges Köhler) and Sir Gregory Winter. Milstein and Köhler received the Nobel Prize in 1984 for their 1975 work on monoclonal antibodies. Sir Gregory's work with Milstein in 1986 at Cambridge's MRC Laboratory, through the application of genetic engineering, led to the development of monoclonal antibodies for therapeutic drugs. Winter's further work enabled the generation of human antibodies in bacteria, bypassing the need to immunize humans. Monoclonal antibodies now account for a third of all new pharmaceutical treatments and generate over US\$32 Bn in market terms ${ }^{8}$. Royalties from Winter's work have generated over $₫ 300 \mathrm{~m}$ for the MRC in royalties from licenses issued to 50 companies. Winter went on to found Cambridge Antibody Technology, with colleague David Chiswell, which was acquired by Astra Zeneca in 2006 for $£ 702 \mathrm{~m}$. In the same year, GlaxoSmithKline acquired Domantis for

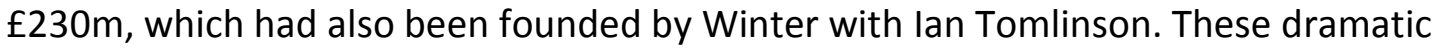
examples show how science and technology, coupled to support from national research councils can generate breakthroughs of immense value to society as well as creating enormous economic benefits.

There are also examples of Fellows whose research led to innovation and exploitation where the Fellow involved decided to support the work of The Royal Society. Sir Edward P. Abraham was a distinguished biochemist, who worked on the development of Penicillin (working with Howard Florey) and later cephalosporin, an antibiotic used to combat penicillin-resistant bacteria in pneumonia septicaemia and bronchitis. His patent on cephalosporin generated a substantial income and Abraham used these funds to generate two charitable trusts. The Royal Society and its work were generously supported by these trusts for many years.

6 House of Lords Science and Technology Committee (2009). Genomic Medicine. The Stationery Office: (London, 2009)

7 Academy of Medical Sciences (2010). Reaping the Rewards: a vision for UK medical science. Academy of Medical Sciences (London, 2010).

8 BBSRC (2009) Science making and economic difference. www.bbsrc.ac.uk/science/impact/economicimpacts.aspx. 


\section{Supporting a Culture of Innovation}

The Royal Society has for many centuries engaged with government, universities and industry to promote science, and innovation. In 2006, the 'UK Mind to Market' delegation was put together to showcase the UK's science innovation-industry sector at the India 'R\&D 2006: Mind to Market' conference, and to allow for the exchange of information and the exploration of opportunities for UK-India collaboration in promoting innovation and wealth creation through science. The visit was organised by the Royal Society and supported by UK Trade \& Investment (UKTI) and the UK Office of Science and Innovation (OSI) under the Indo-UK Science Networking Programme. The conference and networking meetings were hosted by the Federation of Indian Chambers of Commerce and Industry (FICCI), the Indian National Science \& Technology Entrepreneurship Development Board (NSTEDB) and the British High Commission in India. The subsequent report summarised the key issues and challenges that emerged from the networking visit.

More recently and topically, The Royal Society hosted the Innovation Summit in December 2009 , organised by leading universities and technology companies to explore the way that innovation can lead the economy out of recession. It addressed the controversial issue of whether universities that focus on protecting intellectual property are helping or hindering the innovation process.

\section{Funding for Innovation and Enterprise}

The role of venture capital and private equity in funding start-up businesses and spin-outs has become well established over the past twenty five years. The Royal Society Enterprise Fund has been created to make equity investments in innovative early-stage businesses emerging from the science base in the UK and elsewhere. The Fund leverages the Royal Society's technical and scientific network, the extensive science policy work and the flexible time horizons for investment. The focus is on early-stage investment opportunities and the Fund is run on a commercial basis. In order to ensure long-term sustainability, the Fund is financed from donations to the 350th Anniversary Campaign. The Fund is intended to be evergreen, with financial gains recycled for reinvestment in future innovative technologybased opportunities. The operation of the Fund complements the many other activities supported by the Royal Society and designed to encourage the exploitation of science for societal benefit. Investments are made in start-up companies who can demonstrate they have outstanding scientific innovation and which have real commercial potential. The Royal Society's networks and relationships are used to highlight and then calibrate investment opportunities. The Fund has a goal to raise $f 20$ million and aims to attract external investment activity into early-stage companies and to generate long-term financial returns, which are recycled back into the Fund. It is intended to serve as a model for the successful commercial application of the results of outstanding research.

The Enterprise Fund made its first investment in August 2009 in the company Novacem which is developing a new generation of carbon negative cement systems. The technology is based on research from Imperial College London. The annual production of traditional Portland cement is over 2.5 billion tonnes and is responsible for $5 \%$ of global carbon dioxide emissions with cement production expected to double by 2050. In contrast to Portland 
cement, Novacem's cement absorbs more carbon dioxide than it emits over its life cycle.

Widespread adoption of this revolutionary new material has the potential to transform the cement industry from a significant emitter to a significant absorber of carbon dioxide.

\section{Future Directions}

The Royal Society's major policy study, 'The Scientific Century: securing our future prosperity' ${ }^{5}$, which included the work on The Fruits of Curiosity, has been reviewing the landscape for UK science and innovation policy and exploring its direction over the next ten to twenty years. The study measures the different forms of value created by science, engineering and medicine for the UK's economy and society and will consider the role that science will play in equipping Britain to meet future economic, social and environmental challenges. It is clear that universities play an important role in technology innovation and that the Royal Society and its Fellows have a key role to play in generating future ideas, research and subsequently creating benefits for society and the economy. 